\title{
Effect of Ximelagatran and Warfarin on Stroke Subtypes in Atrial Fibrillation
}

\author{
Jeanne S. Teitelbaum, Rüdiger von Kummer, Knut Gjesdal, Arni Kristinsson, \\ Georg Gahn, Gregory W. Albers, on behalf of the SPORTIF Investigators and the \\ SPORTIF Executive Steering Committee
}

\begin{abstract}
Background and Purpose: The most common stroke subtype among atrial fibrillation (AF) patients not receiving anticoagulants is cardioembolic. In the SPORTIF III and V trials, the oral direct thrombin inhibitor ximelagatran was as effective as warfarin in reducing the risk of stroke in patients with nonvalvular AF. We assessed any differential effect of warfarin versus ximelagatran on the risk and outcome of cardioembolic and noncardioembolic stroke. Methods: 7329 patients with AF and $\geq 1$ risk factors for stroke were randomized to treatment with warfarin (target international normalized ratio 2.0-3.0) or fixed-dose ximelagatran. Strokes were classified into specific subtypes. Therapeutic effect of warfarin and ximelagatran, adverse events, and stroke outcomes were assessed according to stroke subtype. Results: The annual stroke rate was low for both cardioembolic (ximelagatran, $0.39 \%$; warfarin, $0.47 \%$ ) and noncardioembolic stroke (ximelagatran, $0.57 \%$; warfarin, $0.37 \%$ ). In ischemic strokes, $33.9 \%$ (ximelagatran) and $34.3 \%$ (warfarin) had strokes of presumed cardioembolic origin. When fatal stroke, disabling stroke, myocardial infarction, and death from any cause were combined as poor outcome, patients with cardioembolic strokes had the highest rate of poor outcome (40\%) but this was non- significant. Conclusions: In SPORTIF III and V the efficacy of warfarin and ximelagatran were similar for prevention of cardioembolic and noncardioembolic strokes. Overall outcome tended to be worse following cardioembolic stroke. Ximelagatran has been withdrawn from the market due to hepatic side effects, but similar compounds are presently being studied.
\end{abstract}

RÉSUMÉ: Effet du ximelagatran et de la warfarine sur les sous-types d'accidents vasculaires cérébraux dans la fibrillation auriculaire. Contexte et Objectif : Le sous-type le plus fréquent d'accident vasculaire cérébral (AVC), chez les patients porteurs de fibrillation auriculaire (FA) qui ne sont pas anticoagulés, est l'AVC d'origine cardioembolique. Dans les essais cliniques SPORTIF III et V, un inhibiteur direct de la thrombine, le ximelagatran, administré par voie orale, était aussi efficace que la warfarine pour diminuer le risque d'AVC chez les patients atteints de FA non valvulaire. Nous avons évalué l'effet de ces deux agents sur le risque et l'issue d'un AVC cardioembolique et non cardioembolique. Méthodes : Sept mille trois cent vingt-neuf patients atteints de FA, porteurs d'un facteur de risque d'AVC ou plus, ont été randomisés à l'un des deux traitements suivants : la warfarine (INR cible de 2,0 à 3,0) ou une dose fixe de ximelagatran. Les AVC étaient classifiés en sous-types spécifiques. L'effet thérapeutique de la warfarine et du ximelagatran, les effets indésirables et l'issue des AVC étaient évalués selon le sous-type d'AVC. Résultats : Le taux annuel d'AVC tant cardioembolique (ximelagatran 0,39\%; warfarine 0,47\%) que non cardioembolique (ximelagatran 0,57\%; warfarine 0,37\%) était faible. Parmi les AVC ischémiques, 33,9\% (ximelagatran) et 34,3\% (warfarine) des AVC ont été présumés d'origine cardioembolique. En combinant l'AVC fatal, l'AVC invalidant, l'infarctus du myocarde et le décès de toutes causes comme issues défavorables, les patients qui avaient subi un AVC cardioembolique avaient le taux le plus élevé d'issues défavorables (40\%), ce qui n'atteignait cependant pas le seuil de la signification statistique. Conclusions : L'efficacité de la warfarine et du ximelagatran étaient similaires au cours des essais cliniques SPORTIF III et V pour prévenir les AVC d'origine cardioembolique et non cadioembolique. L'issue avait tendance à être moins bonne après un AVC cardioembolique. Le ximelagatran a été retiré du marché à cause d'effets secondaires hépatiques. Cependant on étudie présentement des composés similaires.

Can. J. Neurol. Sci. 2008; 35: 160-165

Nonvalvular atrial fibrillation (AF) is implicated in approximately $15 \%$ of ischemic strokes. ${ }^{1}$ In a meta-analysis of six randomized trials, dose-adjusted warfarin decreased stroke occurrence from 4.5 events per 100 patient-years with placebo to 1.5 events per 100 patient-years with warfarin (62\% relative risk reduction)..$^{2,3}$

The pathogenic mechanism for most strokes in AF is thought to be embolism of thrombus precipitated by stasis in the left atrial appendage, but strokes due to concomitant cerebrovascular disease also occur. ${ }^{4}$ In previous analyses of the Stroke Prevention
From the Department of Cardiology (AK), Landspitali University Hospital, Reykjavík, Iceland; Department of Cardiology (KG), Oslo University Hospital Ullevål, Oslo, Norway; Department of Neurology (JST), Montreal Neurological Institute and Hospital, Montreal, Quebec, Canada; Departments of Neurology (GG) and Neuroradiology (RvK), University of Technology, Dresden, Germany; Stanford University Medical Center (GWA), Stanford, CA, USA.

Received December 6, 2006. Final Revisions Submitted November 21, 2007. Reprint requests to: Jeanne S. Teitelbaum, Department of Neurology, Montreal Neurological Institute and Hospital, 3801 University Avenue, Montreal, Quebec, H3A 2B4, Canada. 
in Atrial Fibrillation Trials (SPAF I and II), about two-thirds of strokes were classified as cardioembolic. ${ }^{5,6}$ Aspirin (ASA) was shown to have a greater effect on preventing noncardioembolic strokes than those classified as cardioembolic. ${ }^{5}$ In contrast, warfarin had greatest impact on cardioembolic events. ${ }^{6}$ Recent data from two large double-blind randomized trials (Stroke Prevention using an ORal direct Thrombin Inhibitor in atrial Fibrillation [SPORTIF] III and V) indicate that the oral direct thrombin inhibitor ximelagatran is non-inferior to warfarin in reducing the risk of stroke in patients with nonvalvular AF and at least one additional risk factor for stroke. ${ }^{7,8}$ The objectives of this substudy are to assess the ischemic stroke mechanisms in the patients enrolled in both SPORTIF trials, and evaluate whether treatment with warfarin versus ximelagatran had a differential effect on the risk of cardioembolic versus noncardioembolic stroke.

\section{Material AND Methods}

The SPORTIF III and SPORTIF V studies were both phase III prospective randomized clinical trials involving AF patients with a high risk of stroke. SPORTIF V was a double-blind study comparing adjusted-dose warfarin (target international normalized ratio 2.0-3.0) to fixed-dose ximelagatran $(36 \mathrm{mg}$ twice daily). SPORTIF III was an open-label study similar in all other aspects to SPORTIF V. The rationale, design, and patient characteristics have been previously described. ${ }^{9}$ Although SPORTIF III was not blinded, the study affiliated neurologists and the Central Events Adjudication Committee (CEAC) were not aware of the antithrombotic therapy administered. Entry criteria were based on current guidelines for anticoagulation and required at least one of the following risk factors in addition to persistent or paroxysmal nonvalvular AF: previous stroke, transient ischemic attack (TIA), or systemic embolism; hypertension; left ventricular dysfunction (ejection fraction $<40 \%$ or symptomatic heart failure); age 75 years or older; or age 65 years or older with coronary disease or diabetes.,10

Clinical characteristics were balanced between treatment groups $^{9}$ and similar to those of cohorts in earlier trials demonstrating superiority of warfarin over placebo for prevention of AF-related stroke. ${ }^{7,8}$ Primary events (ischemic or hemorrhagic stroke, or systemic embolism) were evaluated as early after onset as feasible, based on clinical findings and results

Table 1: Criteria for classification of ischemic stroke

\section{Cardioembolic (includes definite and probable)}

All of the following:

No antecedent TIA in the same vascular distribution within two weeks of stroke onset

Maximal neurological deficit at stroke onset

$\mathrm{CT}$ or MRI evidence of lesion $\geq 20 \mathrm{~mm}$ involving cortex or symptoms suggesting cortical involvement

Arterial imaging showing no evidence of significant occlusive disease

Or, one of the following:

At least two of the above, no lacunar syndrome present, and arterial imaging confirming the absence of significant cerebral or cerebellar arterial disease Vertebrobasilar distribution and all of the above true, but no arterial imaging, or arteriogram consistent with cardioembolic mechanism

Noncardioembolic (includes lacunar, atherothrombotic, and miscellaneous causes)

Probable lacunar stroke (all of the following):

Clinical presentations of lacunar syndrome, these being pure motor hemiparesis, pure sensory stroke, ataxic hemiparesis, dysarthria clumsy hand syndrome

Age $>60$ years, or history of hypertension or diabetes mellitus

CT or MRI performed $>72$ hours after stroke shows appropriate subcortical lesion $<20 \mathrm{~mm}$ in diameter or demonstrates no lesion appropriate to the stroke

No obvious other cause of small vessel disease (eg, vasculitis)

Arterial imaging showing no evidence of significant occlusive disease

Probable atherothrombotic stroke (all of the following):

CT or MRI excludes nonischemic lesions and subcortical lesions $<20 \mathrm{~mm}$ in diameter that could account for the symptoms

Arterial imaging showing evidence of significant arterial disease*

Miscellaneous specific causes:

Ischemic stroke due to uncommon causes when sufficient evidence exists to clearly define the cause (e.g. carotid dissection)

Uncertain cause of ischemic stroke

Strokes documented to be ischemic by CT or MRI not fitting into one of the above categories

CT - computerized tomography; MRI - magnetic resonance imaging; TIA - transient ischemic attack; * $\geq 50 \%$ linear stenosis in proximal large vessel supply documented by conventional arteriography, magnetic resonance angiography, or duplex ultrasound; or $\geq 2 \mathrm{~mm}$ ulceration in proximal large vessel supply documented by conventional angiography. 
Table 2: Event rates for stroke subtypes (pooled analysis [SPORTIF III and SPORTIF V]) (total number of events in parentheses)

\begin{tabular}{|c|c|c|c|c|}
\hline & Ximelagatran & Warfarin & & \\
\hline & $\begin{array}{c}\text { Event Rate, } \\
\% / \text { Year }\end{array}$ & $\begin{array}{c}\text { Event Rate, } \\
\% / \text { Year }\end{array}$ & Difference (95\% CI) & $P$ Value* \\
\hline $\begin{array}{l}\text { Cardioembolic } \\
\text { strokes }\end{array}$ & $\begin{array}{l}0.39 \\
(19)\end{array}$ & $\begin{array}{l}0.47 \\
(24)\end{array}$ & $-0.08(-0.34$ to 0.17$)$ & 0.54 \\
\hline $\begin{array}{l}\text { Noncardioembolic } \\
\text { strokes }\end{array}$ & $\begin{array}{l}0.57 \\
(28)\end{array}$ & $\begin{array}{l}0.37 \\
(19)\end{array}$ & $0.20(-0.07$ to 0.47$)$ & 0.15 \\
\hline $\begin{array}{l}\text { Ischemic strokes } \\
\text { (uncertain cause) }\end{array}$ & $\begin{array}{c}0.18 \\
(9)\end{array}$ & $\begin{array}{l}0.53 \\
(27)\end{array}$ & $-0.35(-0.58$ to -0.11$)$ & $<0.01$ \\
\hline $\begin{array}{l}\text { Primary brain } \\
\text { hemorrhage }\end{array}$ & $\begin{array}{c}0.10 \\
(5)\end{array}$ & $\begin{array}{c}0.18 \\
(9)\end{array}$ & $-0.08(-0.22$ to 0.07$)$ & 0.32 \\
\hline
\end{tabular}

CI - confidence interval; *log-rank (Mantel-Haenszel) test).

of computerized tomographic (CT) or magnetic resonance imaging (MRI) of the brain. A majority of patients (89\%) had a CT or MRI as part of their assessment. To increase detection of vascular events, a standard questionnaire was administered by phone every six months, and positive responses would lead to additional evaluation by study-affiliated neurologists (also blinded to treatment).

An independent, blinded CEAC then reviewed the reports for both SPORTIF studies. The stroke subtypes were determined by the CEAC according to a predetermined set of criteria used in the SPAF trials ${ }^{5}$ (Table 1). All strokes were considered ischemic except primary brain hemorrhages. Primary brain hemorrhages include intracerebral hematoma and subarachnoid hemorrhages. Subdural and epidural hematomas were counted as serious adverse events and were included with the systemic bleeding events. Ischemic strokes with hemorrhagic transformation were included in the ischemic group, but were identified as a subgroup for later analysis. In those patients with hemorrhagic transformation, the size of the hemorrhage was not recorded. Ischemic strokes were classified as probably cardioembolic, probably noncardioembolic, or of uncertain cause. Noncardioembolic causes included large vessel atherosclerosis, lacunes, and miscellaneous known etiologies. If the focal neurological event lasted less than 24 hours, it was classified as a TIA. This classification is a clinical one, and does not change according to CT result. In the cases where a subject had two different types of stroke, both stroke subtypes were included.

Patients who died within 30 days of the onset of stroke were regarded as having a fatal stroke. A stroke was defined as having a poor outcome if it met one or more of the following criteria: an increase (relative to screening) of the Modified Rankin score to a final score of three or more when tested at three months post stroke; a decrease (relative to screening) in the Barthel score to $\leq 60$ at three months post stroke; or a fatal stroke.
In order to define the effects of ximelagatran versus warfarin, strokes were analyzed using an on-treatment analysis. For this analysis, all endpoints that occurred after more than 30 consecutive or 60 cumulative days of randomized treatment were excluded. Strokes occurring in both studies (SPORTIF III and V) were pooled for analysis of the relationship between stroke subtypes, clinical outcomes, and antithrombotic therapy, thereby using the largest possible number of events. In this study, we also analyzed the occurrence of myocardial infarction (MI), fatal stroke, disabling stroke, and death during the on-treatment period.

\section{Statistical Analysis}

Event rates (\% per patient-year) are presented for each stroke subtype by study (and as a pooled population) and by treatment. A constant event rate with exponentially distributed time to event was assumed, where the patient years are the denominator and the number of patients with at least one event is the numerator. ${ }^{9}$ $P$ values are from log-rank tests done to test differences between treatment group event rates.

Assessment of adverse events according to stroke subtype was performed using a Pearson chi-square test for independence. For tests involving low event numbers, Fisher's exact test was used.

\section{RESULTS}

\section{Number of Patients with Events by Stroke Subtype}

When the results of SPORTIF III and V were combined, among a total of 7329 participants, 126 patients had at least one ischemic stroke and 14 had a primary brain hemorrhage during the on-treatment period. In those patients taking warfarin (78 patients with strokes out of 3665 total), 9 patients had strokes which were primary brain hemorrhages (9/78 or $11 \%), 24$ had 
strokes which were considered probably cardioembolic, 19 had strokes which were probably noncardioembolic, and 27 had ischemic strokes which could not be classified. Hence, in the warfarin group, $30.4 \%$ (24/78) of all patients with strokes, and $34.3 \%(24 / 70)$ of all patients with ischemic strokes had strokes considered cardioembolic in origin. Among patients with classifiable ischemic strokes, 55.8\% (24/43) had cardioembolic strokes.

In the ximelagatran group (61 patients with strokes out of 3664 total), 5 patients had events which were primary brain hemorrhages (8\%), 19 had ischemic strokes considered probably cardioembolic, 28 had strokes which were probably noncardioembolic, and 9 had ischemic strokes which were of uncertain cause. Therefore, in the ximelagatran group, $31.1 \%$ $(19 / 61)$ of all patients with strokes and $33.9 \%$ of all patients with ischemic strokes had strokes which were likely cardioembolic (19/56). Of the patients with classifiable strokes, $40.4 \%(19 / 47)$ had strokes which were considered to be cardioembolic in origin.

\section{Event Rates in the two Treatment Groups}

The difference in event rates between the treatment groups was significant only for patients with strokes classified to be of uncertain cause where the event rate was higher in the warfarin compared to the ximelagatran group (SPORTIF III and V combined, $0.53 \%$ per patient-year versus $0.18 \%$ per patient-year, respectively; $\mathrm{P}<0.01$ [Table 2]). Otherwise, there was no statistically significant difference in yearly event rates based on stroke subtype.

\section{Incidence of Hemorrhagic Transformation According to Stroke Subtype}

The CEAC recorded the presence of hemorrhagic transformation among the ischemic strokes. A total of eight events were recorded, and none of the transformations were clinically symptomatic. There was no association with any particular stroke subtype, a specific anticoagulant, or with concomitant ASA therapy.

\section{Concomitant ASA Usage and Stroke Incidence}

Concomitant use of ASA was not associated with any reduction in the overall incidence of ischemic stroke $(2.2 \%$ annual stroke rate in patients using concomitant ASA versus $1.8 \%$ without ASA) and there was no apparent reduction in any of the stroke subtypes. The incidence of cardioembolic stroke was $1.1 \%$ and $0.8 \%$ (ximelagatran and warfarin, respectively) in those taking concomitant ASA compared with $0.4 \%$ and $0.6 \%$, respectively, in those on an anticoagulant alone (Table 3). For noncardioembolic stroke, the incidences were $0.9 \%$ and $0.2 \%$ (ximelagatran and warfarin, respectively) in those taking concomitant ASA compared with $0.7 \%$ and $0.6 \%$, respectively, without concomitant ASA. None of these differences were significant, and with non-randomized groups, no conclusions could be drawn. There were no primary brain hemorrhages in the group taking concomitant ASA.

\section{Clinical Outcome According to Stroke Subtype}

Outcome was assessed using the categories 'death by any cause, fatal stroke, disabling stroke, and MI' (Table 4). There was a trend toward more fatal strokes in the cardioembolic group when compared with all other ischemic stroke patients (noncardioembolic and uncertain cause) combined $(\mathrm{P}=0.09)$, as well as a significantly higher incidence when compared directly with the noncardioembolic group ( $\mathrm{P}=0.04$, no longer in Table 4). Among patients who suffered an ischemic stroke, there were a total of four myocardial infarctions; three out of four occurred in patients with a cardioembolic stroke (one occurred in a patient

Table 3: Effect of concomitant ASA usage on stroke incidence

\begin{tabular}{|c|c|c|c|c|}
\hline & Ximelagatran & Ximelagatran & Warfarin & Wafarin + \\
\hline & Alone, $\mathbf{n}^{*}(\%)$ & $+\mathrm{ASA}, \mathrm{n} *(\%)$ & Alone, $\mathbf{n} *(\%)$ & $\mathbf{A S A}, \mathbf{n} *(\%)$ \\
\hline $\begin{array}{l}\text { Cardioembolic } \\
\text { stroke }\end{array}$ & $13(0.4)$ & $6(1.1)$ & $20(0.6)$ & $4(0.8)$ \\
\hline $\begin{array}{l}\text { Noncardioembolic } \\
\text { stroke }\end{array}$ & $23(0.7)$ & $5(0.9)$ & $18(0.6)$ & $1(0.2)$ \\
\hline $\begin{array}{l}\text { Ischemic stroke } \\
\text { (uncertain cause) }\end{array}$ & $9(0.3)$ & $0(0)$ & $21(0.7)$ & $6(1.2)$ \\
\hline $\begin{array}{l}\text { All ischemic } \\
\text { strokes }\end{array}$ & $45(1.4)$ & $11(2.1)$ & $59(1.9)$ & $11(2.3)$ \\
\hline $\begin{array}{l}\text { Primary brain } \\
\text { hemorrhage }\end{array}$ & $5(0.2)$ & $0(0)$ & $9(0.3)$ & $0(0)$ \\
\hline
\end{tabular}

ASA - aspirin; *'n' refers to number of patients with strokes. All comparisons not statistically significant. 
Table 4: Patients with adverse outcomes by specific stroke subtypes

\begin{tabular}{|c|c|c|c|}
\hline & Cardioembolic & Noncardioembolic ${ }^{\#}$ & $P$ \\
\hline & n $(\%) *$ & n $(\%) *$ & Value $\dagger$ \\
\hline Fatal Stroke & 8 (19) & $7(8)$ & 0.09 \\
\hline Disabling stroke & 7 (16) & $13(16)$ & 0.93 \\
\hline Death & $8(19)$ & $7(8)$ & 0.09 \\
\hline Acute MI & $3(7)$ & $1(1)$ & 0.11 \\
\hline Major Bleed & $3(7)$ & $2(2)$ & 0.34 \\
\hline $\begin{array}{l}\text { Fatal or disabling } \\
\text { stroke, death, or } \\
\text { acute MI }\end{array}$ & $17(40)$ & $21(25)$ & 0.10 \\
\hline
\end{tabular}

MI - myocardial infarction; \# - Include ischemic strokes of uncertain cause; * Percent of cardioembolic (of 43 total) and noncardioembolic (of 83 total) strokes; $†$ The statistics are for an association between cardioembolic and noncardioembolic strokes. Because of low cell frequencies, Fisher's exact test is used acute MI and major bleed. A Pearson chi-square test is used for all other outcomes and comparisons.

with a stroke of uncertain cause). When fatal stroke, disabling stroke, MI, and death from any cause were combined under the rubric of poor outcome, patients with a cardioembolic strokes had the highest incidence of poor outcome ( $40 \%$ versus $25 \%$ ), although this was not statistically significant when compared to strokes of noncardioembolic and uncertain causes combined.

\section{Discussion}

Among AF patients who are not receiving anticoagulants, the majority of ischemic strokes are of cardioembolic etiology. However, because of those factors that make them high risk such as age, hypertension and diabetes, they are also at risk for atherothrombotic disease and thrombotic stroke. In previous analyses of the Stroke Prevention in Atrial Fibrillation Trials (SPAF I and II), about two-thirds of strokes were classified as cardioembolic, ${ }^{5,6}$ and warfarin clearly had greatest impact on cardioembolic events. Because of this conclusion, patients with atrial fibrillation at risk for atherosclerotic events are often put on additional ASA without proof of benefit. Ximelagatran was shown to be non-inferior to warfarin for the prevention of ischemic events without the risks of unstable blood levels and without the need for frequent blood tests. It was not known, however, if it had the same differential effect on stroke subgroups. One could only assume that ximelagatran, like warfarin, would decrease cardioembolic events more than atherothrombotic ones. Also, it was possible that outcome might be different with the different drugs, and outcome can be quite different for different stroke subtypes. This is what we set out to study.

In the SPORTIF studies, patients in both the ximelagatran and warfarin groups had extremely low rates of cardioembolic stroke $(0.4 \%$ per year with ximelagatran and $0.5 \%$ per year with warfarin). The expected ratio of cardioembolic to noncardioembolic stroke in patients with AF is typically at least 2:1 in nonanticoagulated patients. In the SPORTIF trials, noncardio- embolic ischemic strokes occurred at essentially the same rate as cardioembolic strokes. These findings suggest that both anticoagulants studied had a greater impact on preventing cardioembolic events. This conclusion is compatible with the results of a similar analysis performed on the SPAF database which suggested that warfarin is more effective for prevention of cardiac embolism while the benefits of ASA are predominantly on noncardioembolic events. , $^{5,6}$

Although our data set is limited by a relatively small number of strokes, there is no evidence that ximelagatran and warfarin differed in their effect on either cardioembolic or noncardioembolic stroke. The lower rate of ischemic stroke of uncertain cause in the ximelagatran group compared with the warfarin group is difficult to interpret due to the small number of events and uncertainty regarding the stroke mechanisms involved. The trend toward fewer primary brain hemorrhages deserves further study.

The SPORTIF III and V trials were not powered to assess the benefits of ASA either alone or in combination with an anticoagulant and ASA use was not randomized. However, about $14 \%$ of the patients took ASA for at least $50 \%$ of the time that they were in the study along with their randomized anticoagulant. These patients did not have lower stroke rates compared with patients who received only an anticoagulant. In fact in a recently reported analysis of the pooled SPORTIF data, after adjustment for potential co-founders in a multivariate analysis, combination therapy with both ASA and anticoagulation was associated with a higher rate of ischemic stroke compared to anticoagulation alone. ${ }^{11}$ In addition, bleeding risks are increased by combination therapy. ${ }^{11,12}$ Our data, however, can not be used to draw any conclusions regarding the combined use of an anticoagulant and aspirin as the analysis was neither randomized nor significant. A randomized trial of anticoagulant with or without ASA would be needed to answer this question. Our data does not allow any conclusions but certainly does not 
support the use of concomitant ASA for simple stroke prevention in patients with AF.

Poor functional outcomes (MI, death, fatal stroke, and disabling stroke) were more common in patients who suffered a cardioembolic event, but the result did not reach statistical significance. This is compatible, however, with several other studies that have reported an increase in medical complications and poorer outcome after cardioembolic stroke. ${ }^{12}$ Our data also demonstrate that there were fewer deaths in the noncardioembolic subgroup compared with the other groups. This finding has also been reported by others. ${ }^{13,14}$ Petty et al, ${ }^{13}$ in their study of outcome survival and recurrence according to subtype, found that despite a higher recurrence rate and more disabling strokes in the noncardioembolic group, the group with ischemic strokes caused by arteriosclerosis had better long-term survival than those with cardiogenic stroke, even after adjustment for age, sex, $\mathrm{AF}$, ischemic heart disease, congestive heart failure, and stroke severity.

Recently, ximelagatran was withdrawn from the market because of adverse events involving hepatic function. One could then wonder as to the pertinence of this and the SPORTIF studies. The studies show that an oral thrombin inhibitor can be as effective as warfarin for the prevention of stroke in patients with atrial fibrillation without the need for frequent monitoring and therefore without the risk of hemorrhage related to INR increases beyond the therapeutic levels. Our study shows that the stroke subtypes prevented by a thrombin inhibitor are similar to those prevented by warfarin. Although this particular antithrombin medication has been withdrawn, others are being developed that will hopefully avoid the hepatic side effects. For this reason, the information gleaned from studying ximelagatran remains pertinent.

\section{SUMMARY}

In the SPORTIF studies the efficacy of warfarin and ximelagatran appeared to be similar for prevention of both cardioembolic and noncardioembolic strokes, and the incidence of primary brain hemorrhage was very low in both treatment groups. Addition of ASA to warfarin or ximelagatran did not appear to provide additional benefit for the prevention of any stroke subtype. Although not statistically significant, overall survival and outcome was poorer in patients with cardioembolic stroke.

\section{Acknowledgement, Funding, and Declaration of CONFLICT OF INTEREST}

Rüdiger von Kummer received honoraria from AstraZeneca as chairman of the Central Event Adjudication Committee for the SPORTIF trials; Knut Gjesdal, Jeanne Teitelbaum and Georg Gahn received honoraria from AstraZeneca for lectures and as members of local advisory boards; and Gregory W. Albers received payments from AstraZeneca to attend meetings related to the SPORTIF trials, and for travel expenses, speaking engagements, and research.

\section{REFERENCES}

1. Cerebral Embolism Task Force. Cardiogenic brain embolism. The second report of the Cerebral Embolism Task Force. Arch Neurol. 1989;46:727-43.

2. Hart RG, Benavente O, McBride R, Pearce LA. Antithrombotic therapy to prevent stroke in patients with atrial fibrillation: a meta-analysis. Ann Intern Med. 1999;131:492-501.

3. Albers GW. Atrial fibrillation and stroke. Three new studies, three remaining questions. Arch Intern Med. 1994;154:1443-8.

4. Bogousslavsky J, van Melle G, Regli F, Kappenberger L. Pathogenesis of anterior circulation stroke in patients with nonvalvular atrial fibrillation. Neurology. 1990;40:1046-50.

5. Miller VT, Rothrock JF, Pearce LA, Feinberg WM, Hart RG, Anderson DC. Stroke Prevention in Atrial Fibrillation Investigators. Ischemic stroke in patients with atrial fibrillation: effect of aspirin according to stroke mechanism. Neurology. 1993;43:32-6.

6. Miller VT, Pearce LA, Feinberg WM, Rothrock JF, Anderson DC, Hart RG. Differential effect of aspirin versus warfarin on clinical stroke types in patients with atrial fibrillation. Neurology. 1996;46:238-40.

7. Olsson SB. Executive Steering Committee on behalf of the SPORTIF III Investigators. Stroke prevention with the oral direct thrombin inhibitor ximelagatran compared with warfarin in patients with non-valvular atrial fibrillation (SPORTIF III): a randomised controlled trial. Lancet. 2003;362:1691-8.

8. Albers GW, Diener HC, Frison L, Grind M, Nevinson M, Partridge $\mathrm{S}$, et al. SPORTIF Executive Steering Committee for the SPORTIF V Investigators. Ximelagatran vs. warfarin for stroke prevention in patients with nonvalvular atrial fibrillation: a randomized trial. JAMA. 2005;293:690-8.

9. Halperin JL. Executive Steering Committee, SPORTIF III and V Study Investigators. Ximelagatran compared with warfarin for the prevention of thromboembolism in patients with nonvalvular atrial fibrillation: rationale, objectives and design of a pair of clinical trials and baseline patient characteristics (SPORTIF III and V). Am Heart J. 2003;146:431-8.

10. Albers GW, Dalen JE, Laupacis A, Manning WJ, Petersen P, Singer DE. Antithrombotic therapy in atrial fibrillation. Chest. 2001;119 Suppl 1:S194-206.

11. Diener HC, Albers GW, Halperin JL, Olsson B, Petersen P, Vahanian A, et al. SPORTIF Executive Steering Committee on behalf of the SPORTIF III and V Investigators. Stroke prevention using the oral direct thrombin inhibitor ximelagatran in patients with non-valvular atrial fibrillation: Pooled analysis from the SPORTIF III and V studies. Cerebrovasc Dis. 2006;21(4):279-93.

12. Sam C, Massaro JM, D'Agostino RB Sr, Levy D, Lambert JW, Wolf PA, et al. Framingham Heart Study. Warfarin and aspirin use and the predictors of major bleeding complications in atrial fibrillation (the Framingham Heart Study). Am J Cardiol. 2004:94:947-51.

13. Petty GW, Brown RD Jr, Whisnant JP, Sicks JD, O'Fallon WM, Wiebers DO. Ischemic stroke subtypes: a population-based study of functional outcome, survival, and recurrence. Stroke. 2000;31:1062-8.

14. Wakita M, Yasaka M, Minematsu K, Yamaguchi T. Effects of anticoagulation on infarct size and clinical outcome in acute cardioembolic stroke. Angiology. 2002;53:551-6. 